\title{
Design of High Ratio DC-DC Converter Applied to PV-Grid Connected Electric Vehicle Charging Station
}

\author{
Dimas Anto Asfani, Daniar Fahmi, Edi Wibowo, Heri Suryoatmojo, \\ Dedet Candra Riawan, and Prabowo
}

Electrical Engineering from Institut Teknologi Sepuluh Nopember Surabaya, Indonesia

\begin{abstract}
In this paper, we propose design of the boost converter with hybrid transformer ratio for hybrid power source charging station. This converter is addressed as DC step up converter. This converter has high ratio conversion that converter to DC bus 24 Volt to AC system 220Volt. The combination between resonance modes and pulse width modulation (PWM) is used to achieve high voltage ratio conversion. The advantage of proposed method is use only single switching device; therefore it is easy to control. Moreover, voltage stress on diode and switching device is relatively low and independent from input voltage. The experiment result show that the converter is able to operates in wide range input voltage and has good conversion efficiency up to $90 \%$. Based on the operation and conversion characteristic, the converter can be operated in power inverter with duty ratio $0.7-0.8$ to synchronizing with $\mathrm{AC}$ system.
\end{abstract}

\section{Introduction}

Solar energy is a very potential energy source in the future because it has many advantages, such as the potential capacity, pollution-free and renewable. This energy is one of the most appropriate energy sources to be combined with the grid. One of the application is the in electric vehicle charging station [1-2]. Charging station is one of the main properties in electric vehicle technology. By utilizing hybrid power source, the expected use of environmentally friendly energy in the charging station will be optimized. Photovoltaic is one of potential green energy to be developed in Indonesia and other equator area in the world.

The use of electric vehicles will increase in line with the issue of the lack of fuel supplies and the implementation of environmentally friendly vehicles [2]. When energy consumption in charging station is increase it can caused several problem in power quality. Based on that problem some challenges in charging station development such as mitigation for stress voltage, voltage fluctuations, voltage drop and distribution transformer damage. Moreover, optimizing the use of renewable energy is also the interesting callanges [2,3]. Some of the methods proposed for such solutions such as power flow management [3], the electric vehicle charging management with load shaving method [4], load forecasting caused by charging electric vehicles on the distribution system [5] and the use of the power converter [6-8]. One electric vehicle charging station architecture that commonly used consists of PV, grid, Energy Storage Unit (ESU), which consists of a battery bank. In this study, there are three converter used as a power conditioning unit [9]. Photovoltaic have a low DC voltage output and change along with light intensity. In the most application, the photovoltaic system is use low DC bus that equipped by storage energy devices such as battery. The voltage conversion from low voltage DC system to AC system utility ( $100-230$ Volt) need high conversion device. Mainly, there are two technique used that are transformer and high ratio converter. When power transformer is used, it can be installed at inverter output to increase output voltage. While high ratio DCDC converter is used, it should be connected between low voltage DC bus and input of DC-AC inverter. To optimize this system, the step-up voltage converter should have a high ratio; it can work on a wide range of input voltage and has a good high efficiency at high load and low load [10-11].

The clamp-mode coupled-inductor buck-boost converter has been proposed [11]. Leakage energy converter from the coupled-inductor reprocessed to reduce the losses of the converter. 
But the stress on the diode is larger than the output voltage of the DC. Moreover, these converters have high ripple current at the input side. Combination of boost converters, fly back converters, switched-capacitor and the series transformer is proposed [12]. With this development, the boost voltage ratio is increases and the voltage stress on the diode is reduced. However, the efficiency in the low load level operation is small as the switching losses will be dominant in this operation

In photovoltaic application, the converter should have a high voltage ratio of and high efficiency because the load and input voltage range is wide. Based on this consideration, the boost converter topology is proposed by utilizing a hybrid operation mode [13-14]. With this method, the transformer magnetic components can be used more effectively. Ripple current is smaller than coupled-inductor topology, conduction losses in the transformer gets smaller; the voltage stress on the switch is always on the low level and is not affected by changes in the input voltage. In addition, this converter also has a high efficiency when the load level is low [15]. Therefore, the advantages of this topology is has high voltage ratio, can work on a wide range of input voltage and has a high efficiency at all of load levels.

In this paper, we propose design of the boost converter with hybrid transformer ratio for hybrid power source charging station. This converter is addressed to boosting-up DC voltage from DC bus to DC-AC inverter. In order to get high voltage boost ratio, this converter utilizes a hybrid operation mode, which is a combination of a pulse width modulation (PWM) and resonant modes. This converter requires only a single switch so much easier in the controlling. Voltage stress on the switch and the diode is relatively low and is not affected by changes in the input voltage when the output voltage is kept in constant value. The experiment results show that the proposed converter can work on a wide range input voltage and has a high efficiency at all load levels is equal to $\pm 78 \%$. So this converter can be applied into an alternative energy sources that produce low voltage DC such as photovoltaic system in charging station. In this paper, the boost ratio converter with hybrid transformer is designed for application of the system charging station that has a source of energy from the power grid and PV panels as shown in Figure 1. In order to connecting DC bus and AC system, charging station is equipped by transformer-less inverter. This inverter should have high ratio voltage conversion from DC $24 \mathrm{~V}$ to AC 220 Volt.

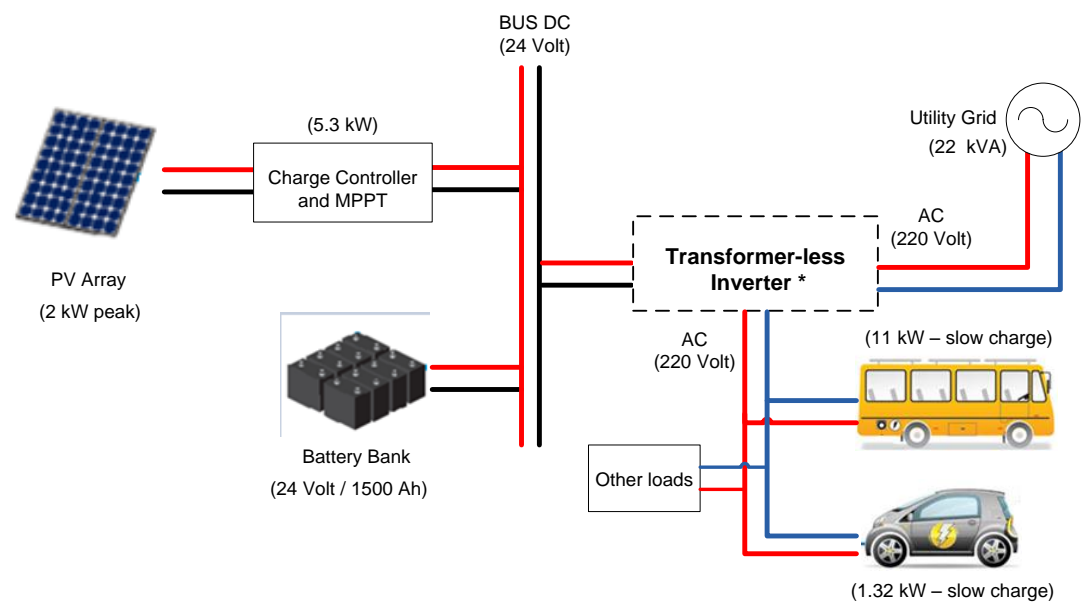

Figure 1. Hybrid source charging station scheme

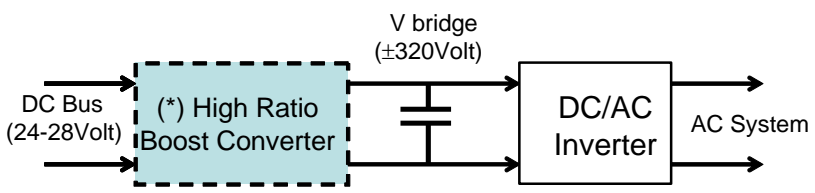

Figure 2. High ration DC-DC Boost Converter 
Table 1. Hybrid source charging station scheme

(*:designed DC converter)

\begin{tabular}{|l|c|}
\hline PV Module & SUP MONO 200 \\
\hline Number of cell & 72 \\
\hline Power rating (W) & 180 \\
\hline Peak power (Pmax) & 200 \\
\hline Voltage rating (Vmp) & 38.16 \\
\hline Current rating (Imp) & 5.26 \\
\hline Open Circuit voltage (Voc) & 45.29 \\
\hline Short Circuit current $($ Isc) & 5.66 \\
\hline Temperatur-power coefficient $\left(\% /{ }^{\circ} \mathrm{C}\right)$ & -0.37 \\
\hline Temperature-voltage coefficient $\left(\% /{ }^{\circ} \mathrm{C}\right)$ & -0.24 \\
\hline Temperature-current coefficient $\left(\% /{ }^{\circ} \mathrm{C}\right)$ & 0.033 \\
\hline
\end{tabular}

Table 2. Battery specification

\begin{tabular}{|l|c|}
\hline Capacity (Ah) & 1500 \\
\hline Voltage rating (V) & 2 \\
\hline Charging current Max (A) & 200 \\
\hline Discharging current Max (A) & 185 \\
\hline Weight $(\mathrm{kg})$ & 115 \\
\hline Dimension $1^{*} \mathrm{w}^{*} \mathrm{~h}(\mathrm{~mm})$ & $340 * 210^{* 677}$ \\
\hline Internal Resistance $(\mathrm{m} \Omega)$ & 0.24 \\
\hline
\end{tabular}

\section{PV-Grid Connected Electric Vehicle Charging Station}

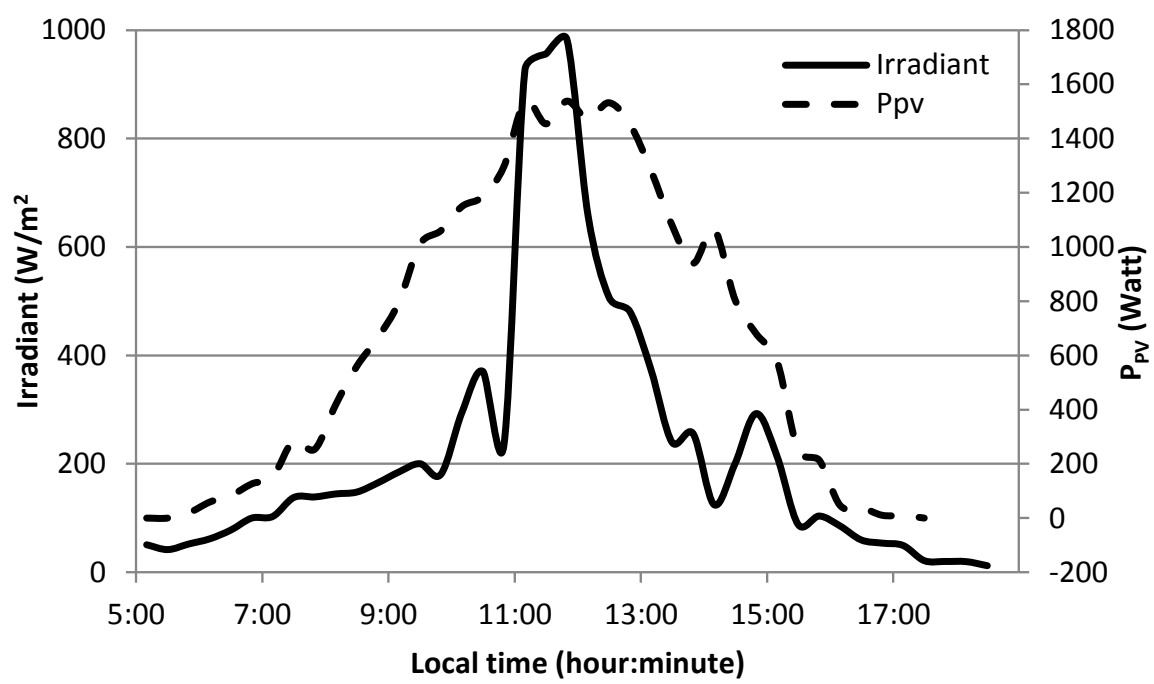

Figure 3. Irradiant and power generated from PV panel

In this study, an electric vehicle charging station is supplied from the grid and solar panels with a nominal voltage and current are 38.16 volts and 5.26 amperes respectively. Solar panel module is commercial module named model Solar Panel 200 Mono. This module has power rating transfer up to 2000 watts peak at full sunlight intensity $(1000 \mathrm{~W} / \mathrm{m} 2)$. The nominal temperature is $25^{\circ} \mathrm{C}$. Panels are connected in series 2 and parallel 5. This connection is resulting nominal voltage and current of 76.32 volts and 26.3 Ampere respectively. Moreover, 
charging station is also equipped by energy storage. In this case, a gel battery is used that has a nominal voltage of 2 volts and a capacity of 1500 Ampere hour. The battery is connected 12 units in series, so that the total nominal value of 24 Volt with a capacity of $1500 \mathrm{Ah}$. The load of this power network is an electric vehicle battery with a capacity of 1320 Watts for normal charging. It need about 10 hours for full charged. Table. 1 and 2 is shows the specification of PV panel and battery storage. Figure 2 shows the measurement result of PV panel within day time. In shows that the PV power is not reach up to 2000 watt in the maximum irradiant because of temperature de-rating.

\section{Converter Design}

\section{A. Converter Scheme}

The main properties of this converter are a hybrid transformer, resonant inductor, switching devices, capacitors and three diodes (clamping diodes, diode and diode output resonance). Metal oxide semiconductor field effect transistor (MOSFET) is used for switching devices. Four capacitors are consisting of capacitor input, clamping capacitor, resonant capacitor and the output capacitor [11]. The schematic circuit of this converter is shown in Figure 4.

Input capacitor $\left(\mathrm{C}_{\mathrm{in}}\right)$ is used to reduce input voltage ripple. Hybrid transformer $(\mathrm{HT})$ is an ideal transformer including a transformer magnetizing inductance $\left(\mathrm{L}_{\mathrm{m}}\right)$ and leak inductance $\left(\mathrm{L}_{\mathrm{k}}\right)$ on the primary side of the transformer. Hybrid transformer has a turns ratio $1: \mathrm{n}$. MOSFET is used for switch $\left(S_{1}\right)$. When the switch is off, the clamping diode $\left(D_{1}\right)$ is used to supply energy from leak inductance of the transformer. While the resonance mode, when the energy in the capacitor charging process resonance $\left(C_{r}\right)$, Diodes resonance $\left(D_{r}\right)$ is used for flowing current into one direction. The diode output $\left(\mathrm{D}_{\mathrm{o}}\right)$ is to drain the energy towards the output side. To reduce the ripple on the output, the output capacitor $\left(C_{o}\right)$ is installed. Resistive load at the output is represented as $R_{0}$.

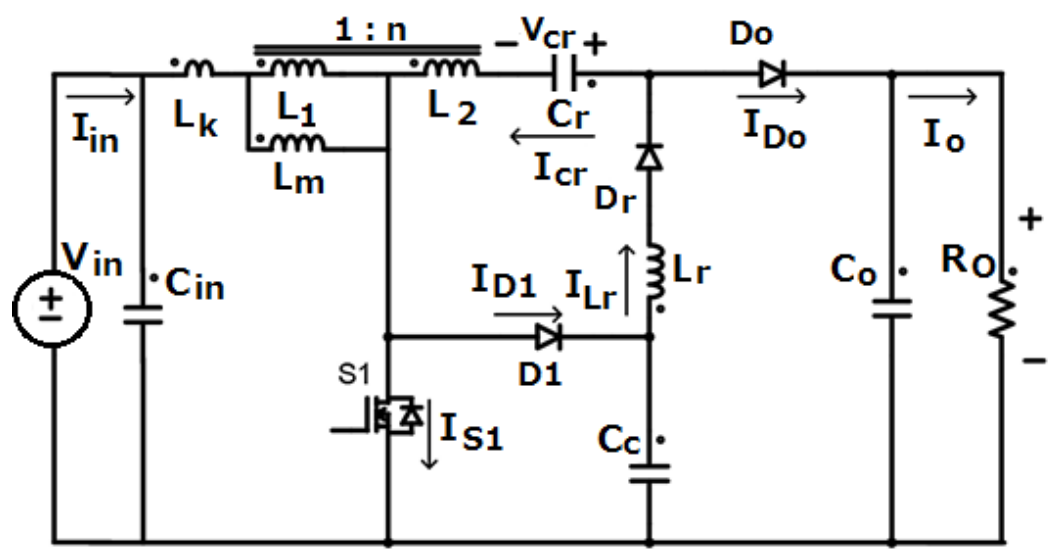

Figure 4. Converter scheme

In the single switching period, the converter has five operation modes [15]. It is assumed that the DC input voltage is an ideal DC sources, all the resistors, diodes, and switches are ideal components. At the time period $t_{0}-t_{1}$, switch $S_{1}$ is active; the magnetization inductance $\left(\mathrm{L}_{\mathrm{m}}\right)$ is charging operation by the input voltage $\left(\mathrm{V}_{\text {in }}\right)$. Magnetization current is increases linearly. In this period, resonant circuit mode is operated. Resonant circuit formed by the secondary side of the transformer hybrid, $\mathrm{C}_{\mathrm{c}}, \mathrm{L}_{\mathrm{r}}, \mathrm{D}_{\mathrm{r}}$ and $\mathrm{C}_{\mathrm{r}}$. In this mode the clamping capacitor $\left(\mathrm{C}_{\mathrm{c}}\right)$ is assumed fully charged. Voltage at secondary side of transformer is $n \times V_{L m}$. Resonant capacitor $\left(C_{r}\right)$ is charged by voltage on the transformer secondary and voltage on the clamping capacitor $\left(\mathrm{C}_{\mathrm{c}}\right)$ through the switch, resonance diode and resonance inductor. At the time period $t_{1}-t_{2}$, switch $S_{1}$ is off. Currents on the primary side and secondary side of the transformer started to charge the 
parasitic capacitor located on the switch. When the voltage on the switch is higher than the voltage clamping capacitor $\left(\mathrm{C}_{\mathrm{c}}\right)$, the clamping diode $\left(\mathrm{D}_{1}\right)$ is active. Energy from leakage inductance $\left(\mathrm{L}_{\mathrm{k}}\right)$ is transmitted to the clamping capacitor $\left(\mathrm{C}_{\mathrm{c}}\right)$ through the clamping diode $\left(\mathrm{D}_{1}\right)$. At the time $t_{2}-t_{3}$, the diode output $\left(D_{o}\right)$ is active. At this time a series circuit formed between $V_{\text {in }}$, $\mathrm{V}_{\mathrm{Lk}}, \mathrm{V}_{\mathrm{LM}}, \mathrm{V}_{\mathrm{L} 2}, \mathrm{~V}_{\mathrm{CR}}$ and $\mathrm{V}_{\mathrm{CO}}$. The energy stored in the magnetizing inductance $\left(\mathrm{L}_{\mathrm{m}}\right)$ and the resonant capacitor $\left(\mathrm{C}_{\mathrm{r}}\right)$ is transferred to the load. Clamping diode $\left(\mathrm{D}_{1}\right)$ remains active during the clamping capacitor $\left(C_{c}\right)$ charging. At the time $t_{3}-t_{4}, D_{1}$ is off. The current flows toward the output side during this period, with magnitude down gradually. The energy stored in the magnetizing inductance and resonant capacitor $\left(C_{r}\right)$ is transferred to the load. At the time $t_{4}-t_{0}$, switch $S_{1}$ is active again. Leakage inductance of the transformer causes the output current $\left(I_{0}\right)$ keep flowing for a short time, and then the diode output is not active at the time $t_{0}$. Furthermore switching period will starts from the beginning. Conversion ratio can be calculated using (1).

$$
M=\frac{V o}{V i n}=\frac{(2+n)}{(1-D)}
$$

In the operation mode $1\left(t_{0}-t_{1}\right)$ and operating mode $2\left(t_{1}-t_{2}\right), D_{1}$ will experience stress voltage. While on the operating mode $1\left(t_{0}-t_{1}\right)$ and on the operating mode $3\left(t_{2}-t_{3}\right), D_{o}$ and diode resonance $\left(D_{r}\right)$ will experience stress voltage. The stress voltage level can be calculated from the following equation:

$$
\begin{aligned}
& V_{D S}=V_{D I}=V_{C c}=\frac{V_{o u t}}{(n+2)} \\
& V_{D o}=V_{d r}=V_{o}-V_{C c}=\frac{(n+1) V_{o}}{(n+2)}
\end{aligned}
$$

Resonance period and frequency of the converter can be calculated by equation (4) and (5).

$$
\begin{aligned}
& T_{r}=2 \pi \sqrt{L_{r_{-} t o t} C_{r}} \\
& f_{r}=\frac{1}{T_{r}}(2.5)
\end{aligned}
$$

Table 3. Design Parameter

\begin{tabular}{lr}
\hline \hline \multicolumn{1}{c}{ Parameter } & \multicolumn{1}{c}{ Value } \\
\hline Switching frequency & $62,5 \mathrm{kHz}$ \\
Power Output & $40 \mathrm{~W}$ \\
Voltage Output (max) & $150 \mathrm{~V}$ \\
Voltage Input (min) & $20 \mathrm{~V}$ \\
Voltage Input (max) & $30 \mathrm{~V}$ \\
Winding ratio $(\mathrm{n})$ & 1 \\
Voltage ripple $\mathrm{Cr}\left(\Delta \mathrm{v}_{\mathrm{Cr}}\right)$ & $1.42 \%$ \\
\hline
\end{tabular}

Table 4. Hardware Device Parameter

\begin{tabular}{lr}
\hline \hline \multicolumn{1}{c}{ Parameter } & \multicolumn{2}{c}{ Value } \\
\hline Transformer & Ferit core ETD 34 \\
& $\mathrm{Np}: \mathrm{Ns}=12: 12$ \\
& $\mathrm{Lm}=152 \mu \mathrm{H}$ \\
MOSFET & IRF540N \\
Dioda (D1, Dr, dan Do $)$ & MUR 1560 \\
Capasitor Input $\left(\mathrm{C}_{\mathrm{in}}\right)$ & $47 \mu \mathrm{F} / 100 \mathrm{~V}$ \\
Capasitor Resonance $\left(\mathrm{C}_{\mathrm{r}}\right)$ & $1 \mu \mathrm{F} / 600 \mathrm{~V}$ \\
Capasitor Clamping $\left(\mathrm{C}_{\mathrm{c}}\right)$ & $22 \mu \mathrm{F} / 100 \mathrm{~V}$ \\
Capasitor Output $\left(\mathrm{C}_{\mathrm{o}}\right)$ & $3 \times 1 \mu \mathrm{F} / 400 \mathrm{~V}$ \\
Inductor Resonance $\left(\mathrm{L}_{\mathrm{r}}\right)$ & $3,3 \mu \mathrm{H}$ \\
MOSFET Driver & $\mathrm{IC} \mathrm{TLP} \mathrm{250}$ \\
\hline \hline
\end{tabular}


In this design, leakage inductance should be considered. $\mathrm{L}_{\mathrm{kp}}$ is leakage inductance on the primary side and $\mathrm{L}_{\mathrm{ks}}$ is leakage inductance on the secondary side.

$$
\begin{aligned}
& L_{r-t o t}=L_{r}+\left(L_{k s}+n^{2} L_{k p}\right) \\
& \Delta v_{C r}=\frac{I_{L m_{-} s e c} T_{o f f}}{2 C_{r}} \\
& I_{l m_{-} s e c}=\frac{I_{O}}{1-D}=\frac{P_{o}}{V_{O}} \frac{1}{1-D}
\end{aligned}
$$

The magnitude of the voltage ripple on the resonant capacitor is $\Delta \mathrm{v}_{\mathrm{Cr}}$, while $\mathrm{I}_{\mathrm{lm} \_ \text {sec }}$ is the average magnetization current referenced secondary side of the transformer. Magnitude of current flowing in the resonant inductor is expressed by $\Delta i_{L r}$.

$$
\Delta i_{L r}=\pi \cdot f_{r} \cdot T_{s} \cdot I_{o}
$$

\section{B. The circuit design of the Boost Converter with Hybrid Transformer}

Some of considerations and target is defined first before calculating other parameter as shown in Table I. Based on the conversion ratio (1), with an input voltage range between $20 \mathrm{~V}$ to $30 \mathrm{~V}$, the duty cycle is 0.4 to 0.6 . When the output power of $40 \mathrm{~W}$, the designed output current $\left(\mathrm{I}_{\mathrm{o}}\right)$ is 0.2667 Ampere and the output resistance $\left(\mathrm{R}_{\mathrm{o}}\right)$ is $562.5 \Omega$. The input current is affected by changes in load and input voltage. By assuming the converter efficiency is $100 \%$, then the range of input current is 1.34 to 2 Ampere. The current average magnetization referred to secondary side can be determined by (8) as follows

$$
\begin{gathered}
I_{L m_{-} s e c}=\frac{I_{O}}{1-D}=\frac{0,2667}{1-0,5}=0,5334 \mathrm{~A} \\
\Delta v_{C r}=1,422 \% .150 \mathrm{~V}=2,133 \mathrm{~V}
\end{gathered}
$$
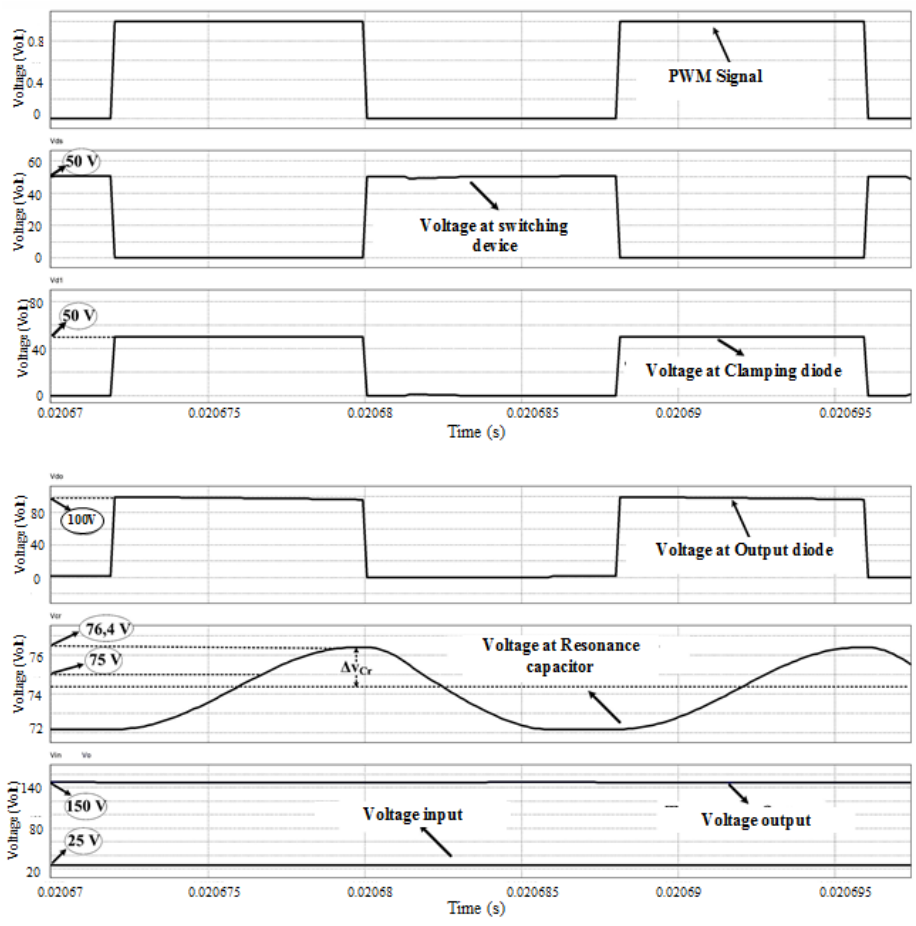

Figure 5. Voltage waveform

By using (7) the capacitance of capacitor $\mathrm{C}_{\mathrm{r}}$ can be determined

$$
C_{r}=\frac{I_{L m \_s e c} T_{o f f}}{2 \Delta v_{C r}}=\frac{0,5334 \cdot 810^{-6}}{2 \cdot 2,133}=1 \mu \mathrm{F}
$$


In order to achieve the voltage stress on the switch is nearly equal to the voltage clamping capacitor $\left(\mathrm{C}_{\mathrm{c}}\right)$, therefore the value of the resonant capacitor $\left(\mathrm{C}_{\mathrm{r}}\right)$ must be much smaller than the value of the clamping capacitor $\left(\mathrm{C}_{\mathrm{c}}\right)$. Considering this factor, the value of the clamping capacitor $\left(\mathrm{C}_{\mathrm{c}}\right)$ is defined as $22 \mu \mathrm{F}$. Resonance period can be calculated from (5)

$$
T_{r}=\frac{1}{f_{r}}=\frac{1}{62500}=16 \mu \mathrm{s}
$$

Inductance $\mathrm{L}_{\mathrm{r}_{-} \text {tot }}$ is calculated from (4)

$$
L_{r-t o t}=\frac{\left(\frac{T_{r}}{2 . \pi}\right)^{2}}{C_{r}}=\frac{\left(\frac{1610^{-6}}{2 . \pi}\right)^{2}}{1.10^{-6}}=6,4846 \mu \mathrm{H}
$$

It is assumed in the design; leakage inductance of transformer $\left(\mathrm{L}_{\mathrm{k}}\right)$ is $1.7 \mu \mathrm{H}$. The magnitude of the resonant inductor can be determined by using (6)

$$
L_{r}=6,4846-(1,7)=4,7846 \mu \mathrm{H}
$$

Based on (9), the value of $\Delta \mathrm{i}_{\mathrm{Lr}}$ can be calculated

$$
\Delta i_{L \mathrm{r}}=\pi .62500 .1610^{-6} .0,2667=0,84 \mathrm{~A}
$$

Voltage stress at switching device and clamping diode is calculated using (2).

$$
V_{D S}=\mathrm{V}_{\mathrm{D} 1}=\frac{150}{(1+2)}=50 \mathrm{~V}
$$

Voltage stress at output diode $\left(\mathrm{D}_{\mathrm{o}}\right)$ and resonance diode $\left(\mathrm{D}_{\mathrm{r}}\right)$ are calculated based on (3).

$$
V_{D o}=\mathrm{V}_{\mathrm{Dr}}=\frac{(1+1) \cdot 150}{(1+2)}=100 \mathrm{~V}
$$

\section{Simulation Analysis}

Boost converter circuit simulation with hybrid transformer aims to determine the performance of the converter. Tests carried out with $25 \mathrm{~V}$ input voltage with duty cycle 0.5 , produces an output voltage $150 \mathrm{~V}$. The simulation is done using PSIM software 9.0.3. Figure 5 shows the voltage waveform. When the PWM signal is high then switching device is active, therefore the voltage is equal to zero. When PWM low then the switching device is off, so that there is an open circuit voltage across to switching device.

At this simulation switching device and diodes are in the ideal conditions. The voltage across to switching device is $50 \mathrm{~V}$. The voltage on the diode $\mathrm{D}_{1}$ is equal to the voltage at the switching device. According to the calculations in the design, the voltage on the diode output of $100 \mathrm{~V}$. The voltage on the capacitor $\mathrm{C}_{\mathrm{r}}$ is $\pm 75 \mathrm{~V}$ with $\Delta \mathrm{V}_{\mathrm{Cr}}$ is 2.13 Volt. Current waveform is shown in Figure 6. This waveform is appropriates to the mode of operation and design. Figure 6 shows that there are current flows in the switching device when the PWM signal is high. At this time the switch is active/on. Based on the operation mode, when switching device is active, converter works on the operating mode-1. In this mode, resonant circuit is working. Resonant circuit is composed by the secondary side of the transformer hybrid, $\mathrm{C}_{\mathrm{c}}, \mathrm{L}_{\mathrm{r}}, \mathrm{D}_{\mathrm{r}}$ and $\mathrm{C}_{\mathrm{r}}$. In this resonance mode, current is pass through resonant inductor and resonant capacitor $\left(\mathrm{C}_{\mathrm{r}}\right)$ is charging. A current at resonance diode $\left(\mathrm{I}_{\mathrm{Dr}}\right)$ is equal to the current flowing in the resonant inductor $\left(\mathrm{I}_{\mathrm{LR}}\right)$.

Magnetization current increases gradually when the PWM signal is high and decreases gradually when the PWM signal is low. The current flowing in the clamping diodes $\left(\mathrm{I}_{\mathrm{D} 1}\right)$ represents the charging of the capacitor clamping period $\left(C_{c}\right)$. Clamping diode $\left(D_{1}\right)$ is active at the time of the switch the voltage on the capacitor is greater than the clamping voltage $\left(\mathrm{V}_{\mathrm{CC}}\right)$. The magnitude of the input current is always greater than zero, so this converter categorized to be working on CCM mode (Continuous Conduction Mode). Output diode current represents the current that flows on the output side. Current flows into the output side when the PWM signal low or when the switch is off. After passing through the output capacitor, the output current becomes flat or almost fixed. 


\section{Hardware Implementation and Testing}

Hardware configuration and layout is shown in figure 7. The system consists of a DC voltage source, the boost converter circuit with hybrid transformer, power supply for electronic circuit, pulse width modulation (PWM) generator circuit for MOSFET driver and resistive load. PWM generator circuit is designed to generate $62.5 \mathrm{kHz}$ signal and the duty cycle is able to control.

Boost converter circuit with a transformer hybrid is supplied by DC voltage source. The voltage source can be controlled to feed converter varied into $20-30 \mathrm{~V}$. The controller output voltage is targeted up to $150 \mathrm{~V}$. The duty cycle is varied according to conversion voltage ratio of converter. The parameters of the components that used in this hardware design are shown in Table 2
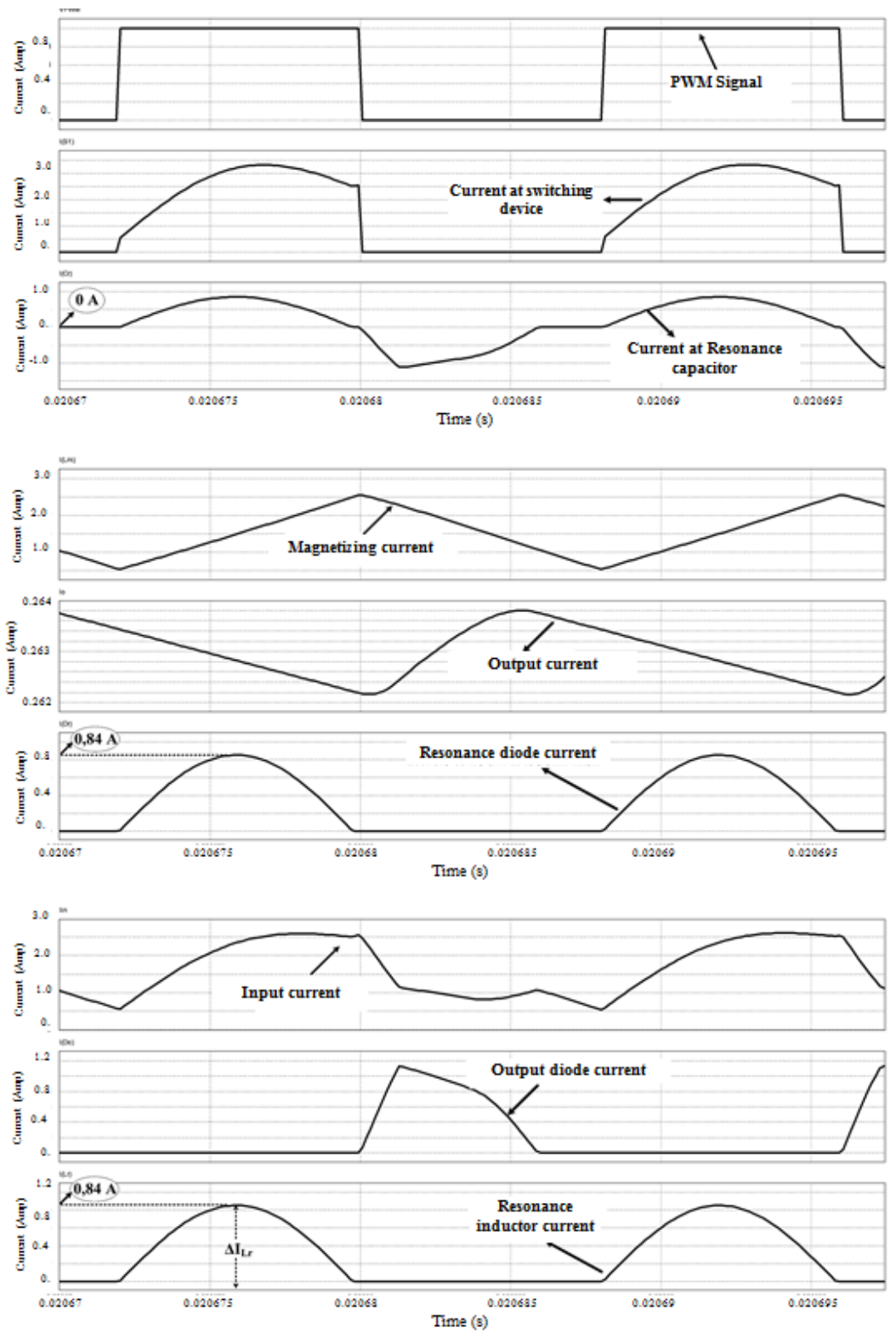

Figure 6. Current waveform 


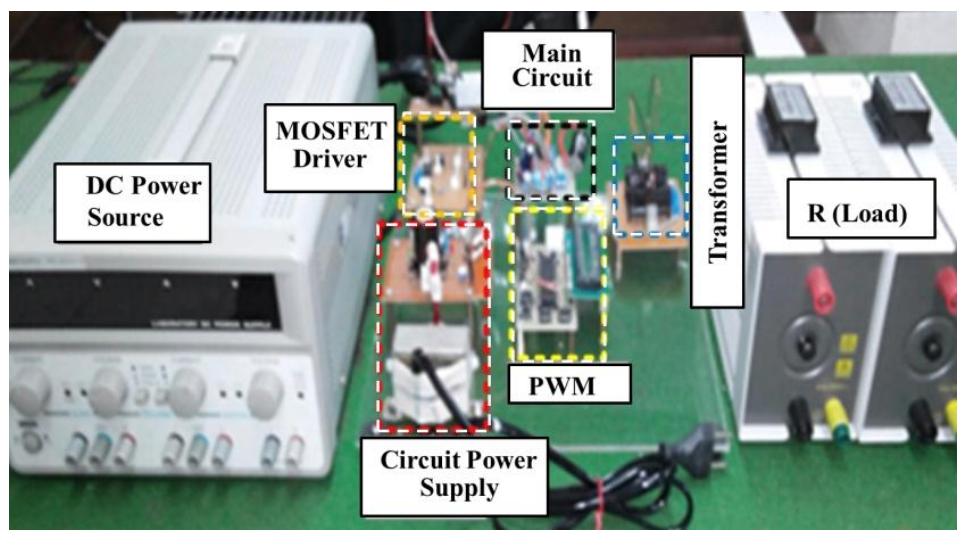

Figure 7. Hardware configuration

\section{A. Waveform Analysis}

As shown in Figure.8, $\mathrm{V}_{\text {gate }}$ is the voltage on the MOSFET gate $\left(\mathrm{V}_{\mathrm{GS}}\right) . \mathrm{V}_{\text {gate }}$ shape is equal to the output voltage shape TLP 250 and also equal to the output voltage of the microcontroller (PWM signal). The Figure show that when the $\mathrm{V}_{\text {gate }}$ is high then MOSFET is active. Conversely, when $V_{\text {gate }}$ is then the MOSFET is off so that the MOSFET voltage is increase. From the picture above shows there is intersection between the voltage and current of MOSFET. The intersection represents losses in the MOSFET. Resonant capacitor current $\left(\mathrm{I}_{\mathrm{cr}}\right)$ is increasing and decreasing indicates charging and discharging periods of the resonant capacitor $\left(C_{r}\right)$. When the MOSFET is active then the resonant capacitor $\left(C_{r}\right)$ is charging. Conversely, when the MOSFET is off then the resonance capacitor is discharging. Moreover, the resonant capacitor charging is indicated by a positive wave, while the negative wave shows resonance capacitor discharging. At the resonant operation mode, current is flow in the resonant inductor. Resonance diode is also active, therefore the diode in the forward bias condition. Resonant inductor current waveform is equal to diode resonance current waveform. Diode output current $\left(\mathrm{I}_{\mathrm{DO}}\right)$ represents the current flowing in to the output side. However, the ripple is still occurred at $\mathrm{I}_{\mathrm{DO}}$. But, at the output current waveform $\left(\mathrm{I}_{\mathrm{co}}\right)$, the ripple is filtered by the output capacitor $\left(\mathrm{C}_{\mathrm{o}}\right)$.

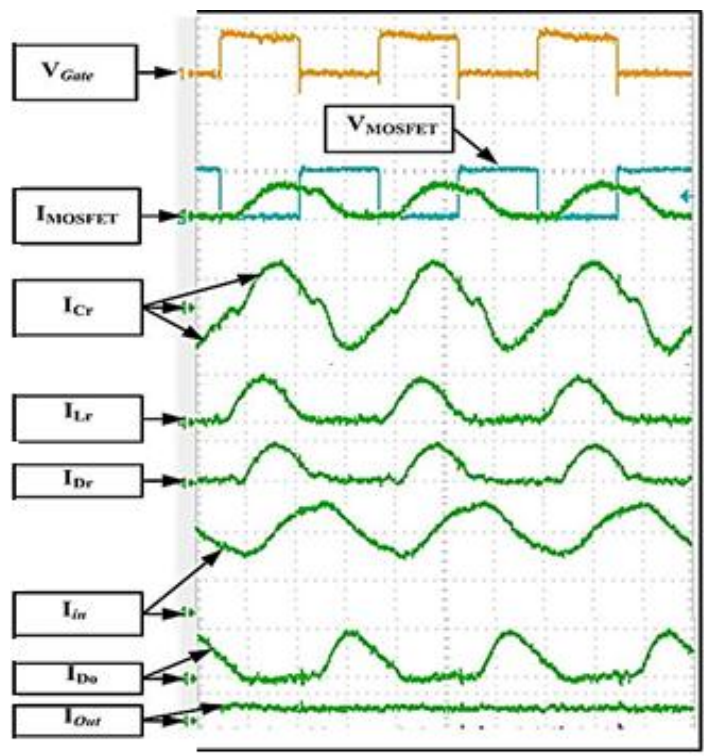

Figure 8. Current and voltage waveform 


\section{B. Voltage Conversion Ratio}

Voltage conversion ratio is calculated based on experiment by regulating duty cycle of converter. Figure. 9 shows the results of a calculated ratio of the output voltage and the measurement results with 25 Volt input voltage. The duty cycle is regulated from 0.1 to 0.5 to reach the output voltage target up to $150 \mathrm{~V}$

\section{Efficiency}

Efficiency is measured and calculated as one of performance indicator of designed converter. The load is varied when input or voltage output is kept in constant. The maximum power output is $40 \mathrm{~W}$. The output voltage is maintained at a voltage of $150 \pm 1$ Volt. Figure. 10 shows converter efficiency when the input voltage is set to $25 \mathrm{~V}$ (the red line) while load is changes. Efficiency is plotted as polynomial regression. The highest efficiency is achieved at the $90 \%$ loading with an output power of $36 \mathrm{~W}$. Average efficiency is $78.24 \%$. In another cases, input voltage is set to be $20 \mathrm{~V}$ and $30 \mathrm{~V}$, while the output voltage is maintained at a voltage of $150 \mathrm{~V}$.

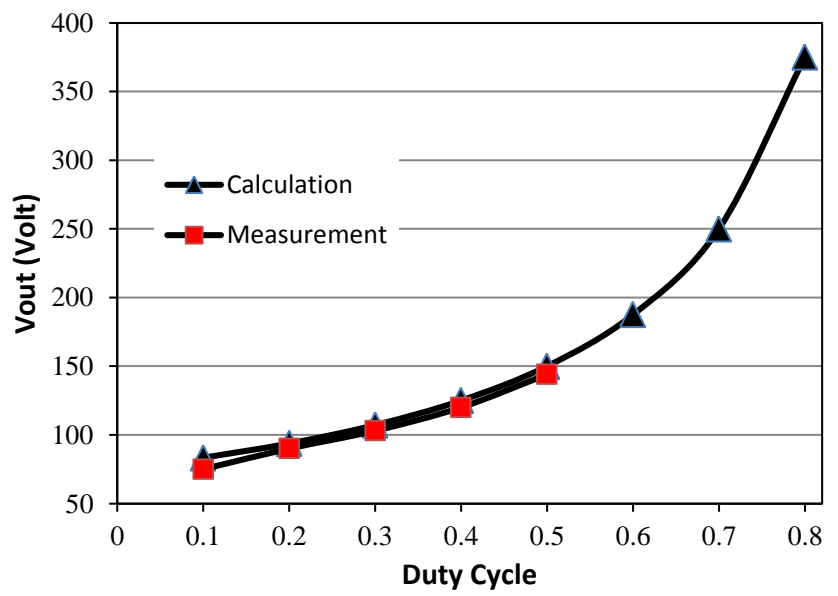

Figure 9. Duty cycle versus voltage output

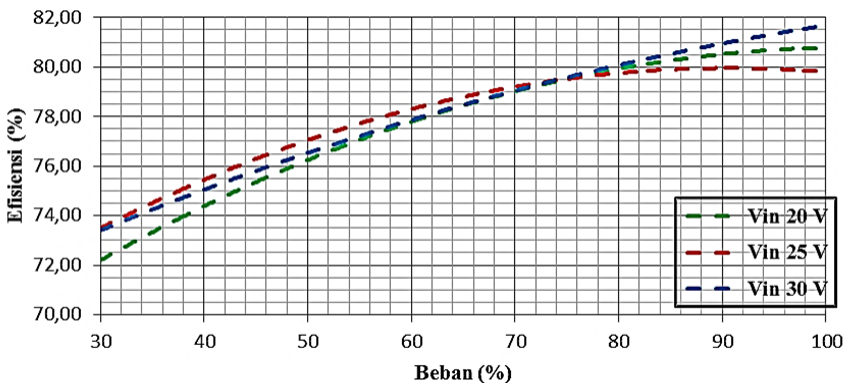

Figure 10. Converter efficiency

\section{Voltage stress at Switch and Diodes}

One of the advantages of the designed converter in this paper is that voltage stress on the MOSFET and the diode below output voltage. Based on (2) and (3) when the output voltage is held constant the voltage stress on the switch and diode is remains constant although the input voltage or load is changes. Figure.11 shows a voltage waveform on the MOSFET $\left(\mathrm{V}_{\mathrm{DS}}\right)$, clamping diode voltage $\left(\mathrm{V}_{\mathrm{D} 1}\right)$, input current waveform and the output voltage waveform. Figure.11.a and 11.b show the change in the load on the output side that can be observed by different output current. It can be seen that when the load changes, the voltage stress on the MOSFET and the clamping diode $\left(\mathrm{D}_{1}\right)$ is remained constant. When the output voltage is 
maintained, even if the input voltage varies, the voltage stress on the MOSFET and diode are constant. Figure. 12 shows the voltage stress on the MOSFET and diode is similar even though the input voltage varies. From the top down is the voltage waveform on the MOSFET $\left(\mathrm{V}_{\text {MOSFET }}\right)$, surge voltage at the diode resonance $\left(\mathrm{D}_{\mathrm{R}}\right)$, input voltage waveform and the output voltage waveform. Voltage stress on the MOSFET ( $\mathrm{V}_{\text {MOSFET }}$ ) is equal to the voltage stress on the clamping diodes $\left(\mathrm{V}_{\mathrm{D} 1}\right)$. The magnitude is $\pm 50 \mathrm{~V}$. The voltage stress on the diode resonance $\left(V_{D R}\right)$ is equal to the voltage stress on the output diode $\left(V_{D O}\right)$. The magnitude is $\pm 100 \mathrm{~V}$. The average value of the voltage MOSFET $\left(\mathrm{V}_{\text {MOSFET }}\right)$ and the average value of the diode voltage resonance $\left(\mathrm{V}_{\mathrm{DR}}\right)$ is different in magnitude. This different is because in order to keep the value of output voltage when the input voltage is different. And then the duty cycle is also different, so average values are different but the same in magnitude.

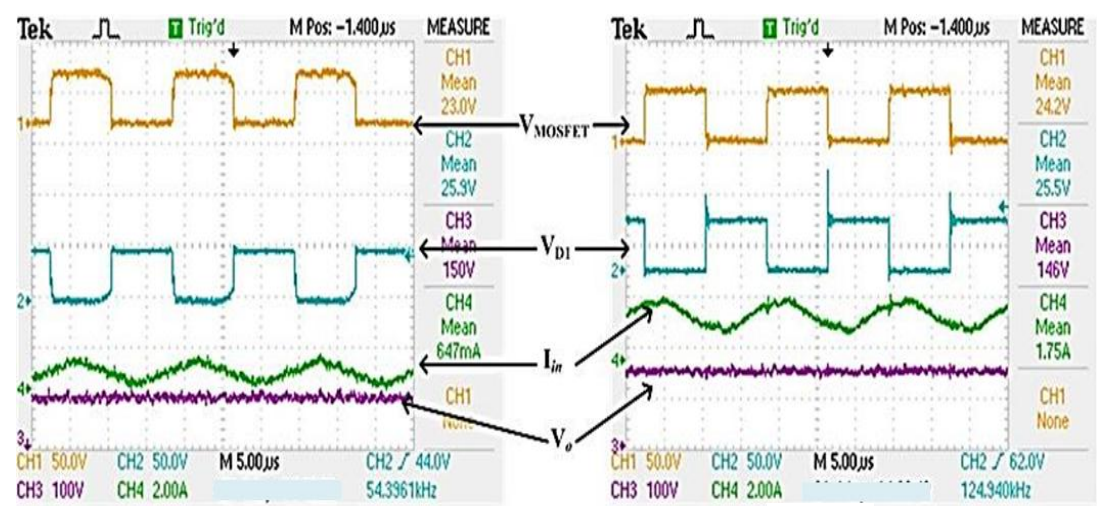

(a)

(b)

Figure 11. Voltage stress $\mathrm{V}_{\mathrm{DS}}$ and $\mathrm{V}_{\mathrm{D} 1}$ for different load (a) $12 \mathrm{~W}$ (b) $40 \mathrm{~W}$

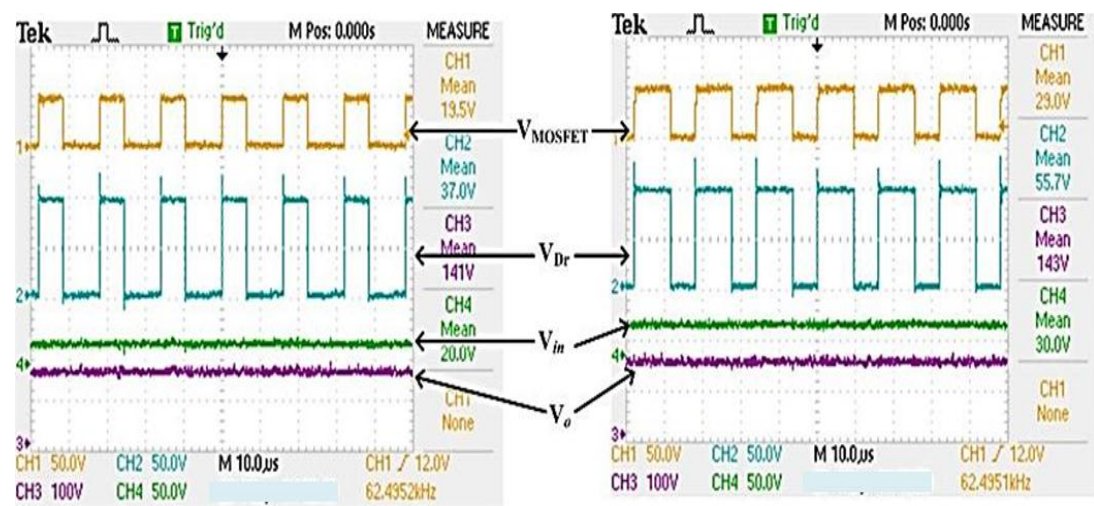

(a)

(b)

Figure 12. Voltage stress for different voltage input (a) $20 \mathrm{~V}$ (b) $30 \mathrm{~V}$

\section{Conclusion}

The DC-DC converter for applications charging station with hybrid power source has been designed. This converter is utilizing a hybrid transformer that resulting high conversion ratio that suitable to support transformer-less inverter. Voltage conversion ratio can be simply increased by raising the value of the turns ratio of the transformer (n). This converter can work on a wide range of input voltages. The highest efficiency is $81 \%$, which achieved at $90 \%$ loading condition. Efficiency at low load levels is not much different from the efficiency at high load. Average efficiency in the prototype is $78 \%$. Moreover, voltage stress on the 
switching device and diode is not affected by load and input voltage changes, when the output voltage is maintained constant.

\section{References}

[1]. Z. Liu, F. Wen, G. Ledwich, "Optimal Planning of Electric-Vehicle Charging Stations in Distribution Systems", in IEEE Transactions On Power Delivery, vol. 28, no. 1, January 2013.

[2]. Tan Ma; Mohammed, O.A., "Optimal Charging of Plug-in Electric Vehicles for a CarPark Infrastructure," Industry Applications, IEEE Transactions on , vol.50, no.4, pp.23232330, July-Aug. 2014

[3]. Preetham Goli, Wajiha Shireen, "PV Integrated Smart Charging of PHEVs Based on DC Link Voltage Sensing”, IEEE Transactions on Smart Grid, Vol. 5, No. 3, May 2014.

[4]. P. Goli, W. Shireen, "PV Integrated Smart Charging of PHEVs Based on DC Link Voltage Sensing," Smart Grid, IEEE Transactions on , vol.5, no.3, pp.1421-1428, May 2014.

[5]. Mukesh Singh, Praveen Kumar, Indrani Kar, "A Multi Charging Station for Electric Vehicles and Its Utilization for Load Management and the Grid Support," Smart Grid, IEEE Transactions on , vol.4, no.2, pp.1026-1037, June 2013

[6]. Nima Ghiasnezhad Omran, ShaahinFilizadeh "Location-Based Forecasting of Vehicular Charging Load on the Distribution System," Smart Grid, IEEE Transactions on , vol.5, no.2, pp.632-641, March 2014

[7]. Lei Shi, Haiping Xu, Dongxu Li, Zengquan Yuan, "A novel high power factor PWM rectifier inverter for electric vehicle charging station," Electrical Machines and Systems (ICEMS), 2011 International Conference on , vol., no., pp.1,6, 20-23 Aug. 2011

[8]. S. Adhikari, Fangxing Li, "Coordinated V-f and P-Q Control of Solar Photovoltaic Generators With MPPT and Battery Storage in Microgrids," Smart Grid, IEEE Transactions on , vol.5, no.3, pp.1270,1281, May 2014.

[9]. Hung-I Hsieh, Cheng-Yuan Tsai, Guan-Chyun Hsieh, "Photovoltaic Burp Charge System on Energy-Saving Configuration by Smart Charge Management," Power Electronics, IEEE Transactions on , vol.29, no.4, pp.1777,1790, April 2014

[10]. Asfani, D.A.; Fahmi, D.; Wibowo, E.; Suryoatmojo, H.; Riawan, D.C.; Prabowo, "Experimental design boost ratio converter with hybrid transformer for hybrid power source charging station," Electrical Engineering and Computer Science (ICEECS), 2014 International Conference on , vol., no., pp.321,325, 24-25 Nov. 2014

[11]. Q. Zhao and F.C. Lee, "High efficiency, high step-up dc-dc converter", IEEE trans. Power Electron., vol. 18, no. 1, pp. 65-73, Jan. 2003.

[12]. R.J. Wai and R.Y. Duan, 'High step-up converter with coupled-inductor", IEEE Trans. Power Electron., vol. 20, no. 5, pp. 1025-1035, Sep. 2005.

[13]. S. Cuk, "Step-down converter having a resonant inductor, a resonant capacitor and a hybrid transformer", U.S. Patent 7915 874, Mar.2011.

[14]. S. Cuk and Z.Zhang, "Voltage step-up switching dc-to-dc converter field of the invention", U.S. Patent 7778 046, Aug.2010.

[15]. Bin Gu, J. Dominic, J. S. Lai, Z. Zao and C. Liu, "High Boost Ratio Hybrid Transformer DC-DC Converter for Photovoltaic Module Applications", IEEE Transactions On Power Electronics, Vol. 28, No. 4, April 2013. 

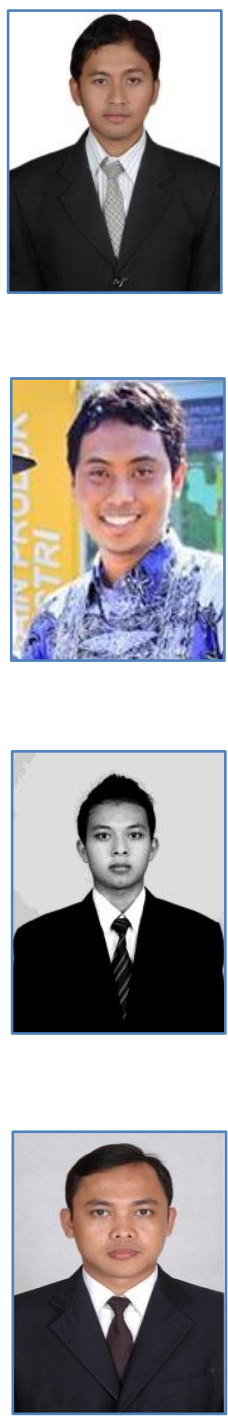

Heri Suryoatmojo. He received his B.Eng, M.T degrees in Electrical Engineering from Institut Teknologi Sepuluh Nopember Surabaya, Indonesia, in 2004 and 2006. Ph.D. degree in the Power System Laboratory Kumamoto University in 2010. He was joined Institut Teknologi Sepuluh Nopember, Surabaya, Indonesia in 2005 as lecture and research asistent. His research concentrates mainly on power electronics and renewable energy.

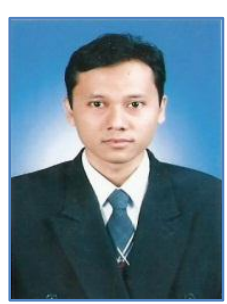

Dedet Candra Riawan. He received his B.Eng, degrees in Electrical Engineering from Institut Teknologi Sepuluh Nopember Surabaya, Indonesia, Master and Ph.D. degree from Curtin University Of Technology. His research concentrates mainly on power electronics and renewable energy.

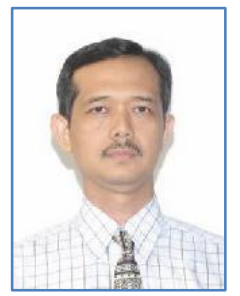
Engineering from Institut Teknologi Sepuluh Nopember Surabaya, Indonesia, in 2004 and 2006. Ph.D. degree in the Power System Laboratory Kumamoto University in 2012. He was joined Institut Teknologi Sepuluh Nopember, Surabaya, Indonesia in 2005 as lecture and research asistent. His research concentrates mainly on fault detection in induction machine and power system.

Daniar Fahmi was born in Surabaya, Indonesia, on 1989. He received his B.Eng, M.T degrees in Electrical Engineering from Institut Teknologi Sepuluh Nopember Surabaya, Indonesia, in 2011 and 2013. He was joined Institut Teknologi Sepuluh Nopember, Surabaya, Indonesia in 2014 as lecture and research asistent. His research concentrates mainly on high voltage engineering.

Edi Wibowo. He received his B.Eng degrees in Electrical Engineering from Institut Teknologi Sepuluh Nopember Surabaya, Indonesia, in 2014. His research concentrates mainly on power inverter.
Dimas Anto Asfani. He received his B.Eng, M.T degrees in Electrical

Prabowo. He received his B.Eng, degrees in Mechanical Engineering from Institut Teknologi Sepuluh Nopember Surabaya, Indonesia, Master and $\mathrm{Ph} . \mathrm{D}$. degree from Hiroshima University. His research concentrates mainly on Heat transfer and Thermal energy conversion. 